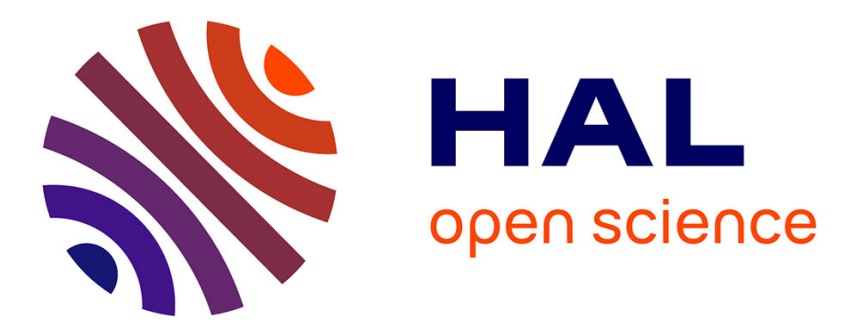

\title{
Umpolung Strategy with 2-Aminothiophenols: Access to 2-Arylbenzothiazine Derivatives from Alkyl Aryl Ketones
}

\author{
T .B. Nguyen, Pascal Retailleau
}

\section{- To cite this version:}

T .B. Nguyen, Pascal Retailleau. Umpolung Strategy with 2-Aminothiophenols: Access to 2Arylbenzothiazine Derivatives from Alkyl Aryl Ketones. Advanced Synthesis and Catalysis, In press, 10.1002/adsc.202000964 . hal-02993861

\section{HAL Id: hal-02993861 \\ https://hal.science/hal-02993861}

Submitted on 27 Nov 2020

HAL is a multi-disciplinary open access archive for the deposit and dissemination of scientific research documents, whether they are published or not. The documents may come from teaching and research institutions in France or abroad, or from public or private research centers.
L'archive ouverte pluridisciplinaire HAL, est destinée au dépôt et à la diffusion de documents scientifiques de niveau recherche, publiés ou non, émanant des établissements d'enseignement et de recherche français ou étrangers, des laboratoires publics ou privés. 
DOI: 10.1002/adsc.201((will be filled in by the editorial staff))

\title{
Umpolung Strategy with 2-Aminothiophenols: Access to 2- Arylbenzothiazine Derivatives from Alkyl Aryl Ketones
}

\author{
Thanh Binh Nguyen, ${ }^{*, a}$ and Pascal Retailleau ${ }^{\mathrm{a}}$
}

a Institut de Chimie des Substances Naturelles, CNRS UPR 2301, Université Paris-Sud, Université Paris-Saclay, 1 avenue de la Terrasse, 91198 Gif-sur-Yvette, France

E-mail: thanh-binh.nguyen@cnrs.fr

Received: (will be filled in by the editorial staff))

Supporting information for this article is available on the WWW under http://dx.doi.org/10.1002/adsc.201\#\#\#\#\#\#.((Please delete if not appropriate))

\begin{abstract}
Strong Brønsted acids were found to catalyze the oxidative condensation of 2-aminothiophenols with aryl alkyl ketones in DMSO to provide a wide range of complex 2-arylbenzothiazines. With acetophenones, dimeric 2arylbenzothiazines were formed. On the other hand, the reaction with propiophenones resulted in 2:1 adducts whereas $1: 1$ adducts were produced with isobutyrophenones, benzoylacetonitrile and ethyl benzoylacetate.
\end{abstract}

Keywords: sulfur; 1,4-benzothiazines; DMSO; redox condensation

Among nitrogen and sulfur heterocycles, 1,4benzothiazines ${ }^{[1]}$ constitute an important motif that is widely present in natural products and bioactive molecules as dimeric and other oligomeric forms. ${ }^{[2]}$ For example, pheomelanins are polymeric structures of melanin pigments in mammalian hair and chicken feathers. ${ }^{[3]}$ Trichochromes are produced from the same sources, of lower molecular weight and usually yellow, red or violet. All these structures contain multiple 1,4benzothiazines motifs.
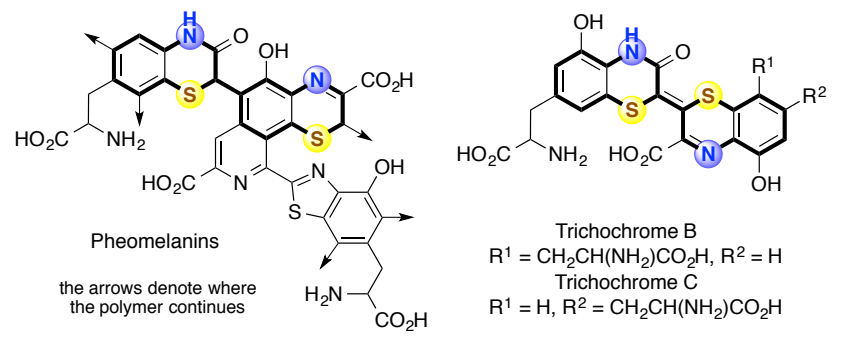

Figure 1. Selected Natural 1,4-Benzothiazines

The synthesis of 1,4-benzothiazine derivatives was based mainly on non-redox condensation reactions of $o$-aminothiophenols, which act as a bis-nucleophile, with a 1,2-bis-electrophile. ${ }^{[4]}$ Since both thiol SH and amino $\mathrm{NH}_{2}$ groups could act as a nucleophile, a frequently encountered issue of this approach is difficulty in controlling regiochemistry of the reactions. To overcome this drawback, the transformation could be performed in a stepwise manner in which the nitrogen or sulfur terminus is temporarily masked or protected and then released later for cyclization. Such a process requires however additional operations of protection/deprotection and thus lower the efficiency of the global transformation.
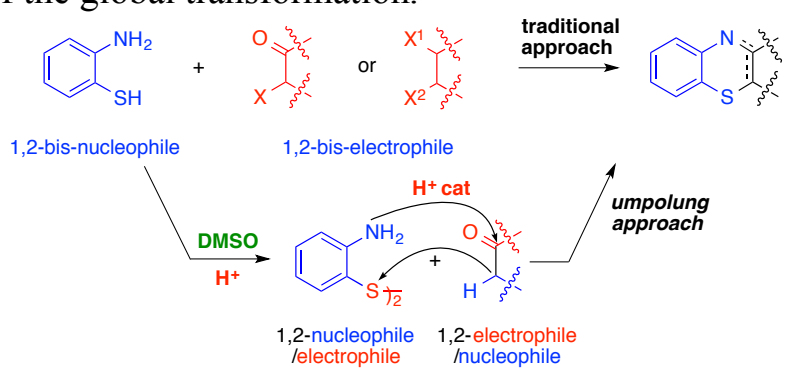

Scheme 1. Umpolung Approach to 1,4-Benzothiazine

In this context, the development of new conditions allowing direct access to original 2-aryl-1,4benzothiazine motif from 2-aminothiophenols and aryl alkyl ketones would be highly desirable. ${ }^{[5]}$ Taking advantage of the facile oxidation of the thiols into the corresponding disulfide and the acid-catalyzed condensation of an amino group with a ketone group, we suggest here the use of 2-aminothiophenols 1 for direct oxidative functionalization of readily available enolizable ketones via an in-situ and easily reversal of polarity of 1 from a 1,2-bis-nucleophile to 1,2nucleophile/electrophile.

We recently reported the reaction of 2aminothiophenol with $\alpha, \alpha^{\prime}$-enolizable ketones such as cycloalkanones or dialkyl ketones to provide spirobis(1,4-benzothiazines) A (Scheme 2). The reaction was efficiently catalyzed by a strong Brønsted acid such as TFA and required only DMSO as an oxidant in near stoichiometric amounts. ${ }^{[6]}$ We were eager to investigate the behavior of $\alpha$-enolizable 
ketones under the similar reaction conditions. Gratifyingly, the reaction conditions applied to acetophenone 2a led to dimeric 1,4-benzothiazine 3aa as a yellow solid that precipitated out of the reaction mixture and readily isolable by a simple filtration in a moderate yield $(60 \%)$.

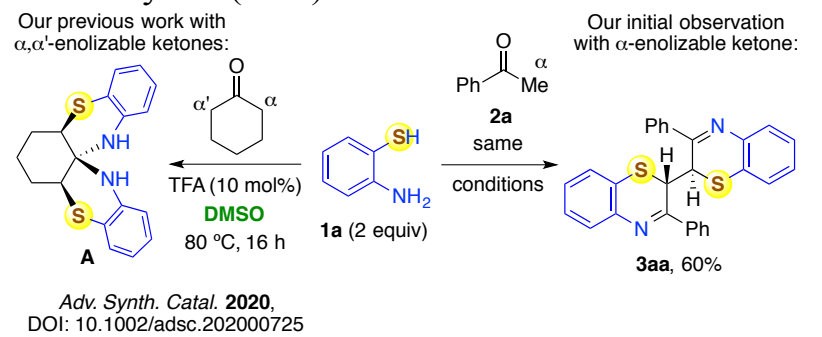

Scheme 2. Oxidative Coupling of 2-Aminothiophenol with Ketones

Previously, access to such dimeric 1,4benzothiazines was based mainly on the condensation of $o$-aminothiophenols with 1,2-biselectrophiles. ${ }^{[7]}$ Recently, 3aa analogues were obtained via a reaction of 2,2'-dithiodianilines and acetophenones in HOAc under aerobic conditions. One of the major disadvantages of this method is the use of AIBN ${ }^{[8]}$ This unstable initiator should be stored at low temperature in the dark to avoid thermal and photochemical decomposition and accidental explosion. Moreover, the reactions were reported only with 2,2'-dithiodianilines, which should be prepared from their monomeric precursors 2-aminothiophenols by an additional oxidation.

Based on this serendipitous observation and the above-mentioned literature precedent, we focused our investigation on such a new reactivity and report here interesting aspects of the reaction of 2aminothiophenols with alkyl aryl ketones in DMSO catalyzed by a strong Brønsted acid. The initial reaction conditions were applied to an equimolar mixture of both starting materials and resulted in an better yield (Table 1, entry 1). The important role of TFA catalyst was further demonstrated. Indeed, when the reaction was performed in the absence of TFA, the reaction proceeded in an uncontrolled way, leading to complex mixtures from which we could isolate 2phenylbenzothiazole 8 in low yield (22\%). In this case, the expected product 3aa was formed only in a trace amount that could be detected by the characteristic ${ }^{1} \mathrm{H}$ NMR signal of the aliphatic $\mathrm{C}-\mathrm{H}$ proton (entry 2). On the other hand, the background reaction conditions could result in higher yield (21\%) of 3aa at a higher temperature $\left(100^{\circ} \mathrm{C}\right)$ (entry 3$)$. When a base such as $\mathrm{DBU}^{[5]}$ or cyclohexylamine was used as a catalyst (entry 4 ) or additive (entry 5), the reactions in both cases stopped at the formation of monomer 3-phenyl$2 H$-benzo $[b][1,4]$ thiazine $\mathbf{7 a}$.

A Lewis acid such as $\mathrm{FeCl}_{3} \bullet 6 \mathrm{H}_{2} \mathrm{O}$ or another Brønsted acid PTSA showed also good catalytic effect (entries 7 and 8). While changing reaction temperatures reduced the yield of 3aa (entries 8 and
10), lower the DMSO amount to only 2 equiv (entry 9) enhanced significantly the reaction. This improvement could be explained by an increase in the concentrations of both starting materials and catalyst and favored the dimerization of the monomeric intermediate 7a to 3aa. We found that the reaction the reaction conducted under an inert atmosphere led to practically the same result (entry 11). The reaction could be performed with 2,2'-dithiodianiline B instead of $\mathbf{1 a}$ (entry 12). Finally, we found that a weak acid such as HOAc was not suitable as a catalyst for this reaction (entry 13).

Table 1. Optimization of the Reaction Conditions

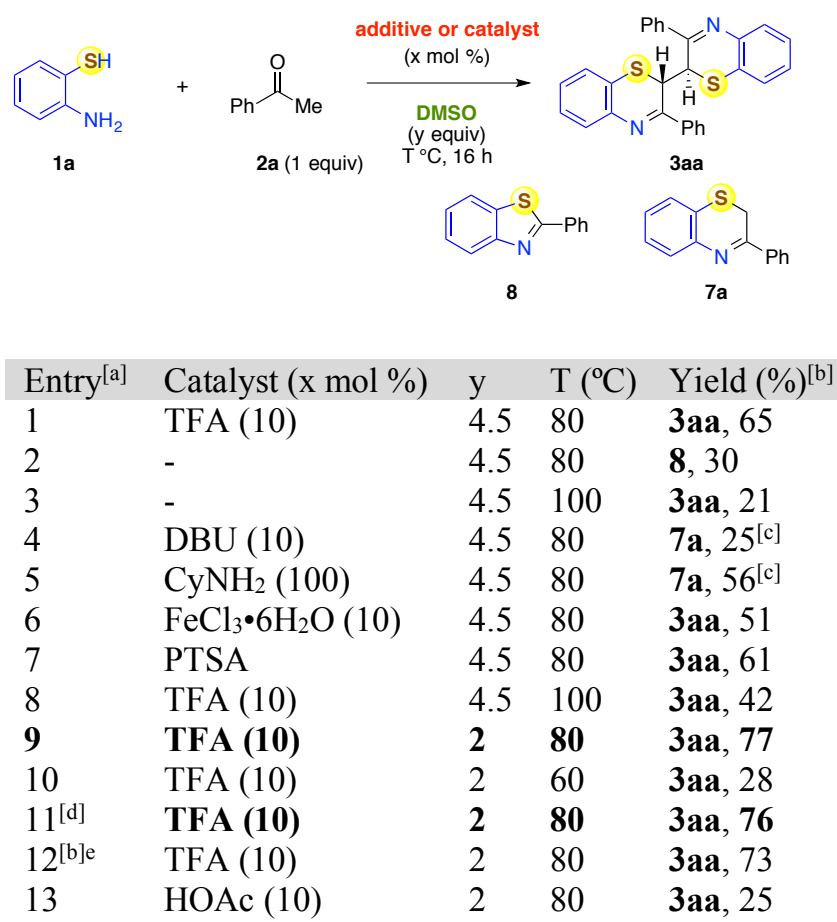

[a] Conditions: 1a ( $1 \mathrm{mmol}, 125 \mathrm{mg})$, acetophenone (1 mmol, $120 \mathrm{mg}$ ), additive or catalyst (x mol \%), DMSO (y mmol) under air. ${ }^{[b]}$ Isolated yield unless otherwise noted. ${ }^{[\mathrm{c}]}$ Determined by ${ }^{1} \mathrm{H}$ NMR. ${ }^{[\mathrm{d}]}$ Reaction performed under an Ar atmosphere. ${ }^{[\mathrm{e}]}$ 2,2'-Dithiodianiline $\mathbf{B}(0.5 \mathrm{mmol})$ were used in place of $\mathbf{1 a}$.

The optimized reaction conditions (Table 1, entry 9) were next applied to a range of aryl methyl ketones (Scheme 3). Functional groups such as alkyl, alkoxy, halogen and cyano were compatible with the reaction conditions, leading to the expected products 3ab-3am in moderate to good yields. In most cases, the products could be isolated by a simple trituration of the reaction mixture with methanol. While good to excellent yields were obtained with alkyl, alkoxy, fluoro, chloro and cyano substituted acetophenones, the reactions were less efficient with $m$ - and $p$-bromo- acetophenones.

In some cases, while the products $\mathbf{3}$ are sparingly soluble in common organic solvents such as chloroform or DMSO, their solubility is significantly enhanced by addition of TFA as exemplified by the case of dimer product 3ad issued from $p$ methoxyacetophenone 2d. The ${ }^{1} \mathrm{H}$ and ${ }^{13} \mathrm{C}$ NMR spectra of $3 \mathrm{ad}$ were recorded in $\mathrm{CDCl}_{3}$ and TFA and 
its crystals for X-ray crystallographic study were obtained as 3ad•2TFA salt from slow evaporation of this salt in chloroform. Acetyl hetarenes derived from thiophene, furan and benzofuran were shown to be competent substrates, providing the expected product 3an, 3ao, 3bo and 3ap in excellent yields.

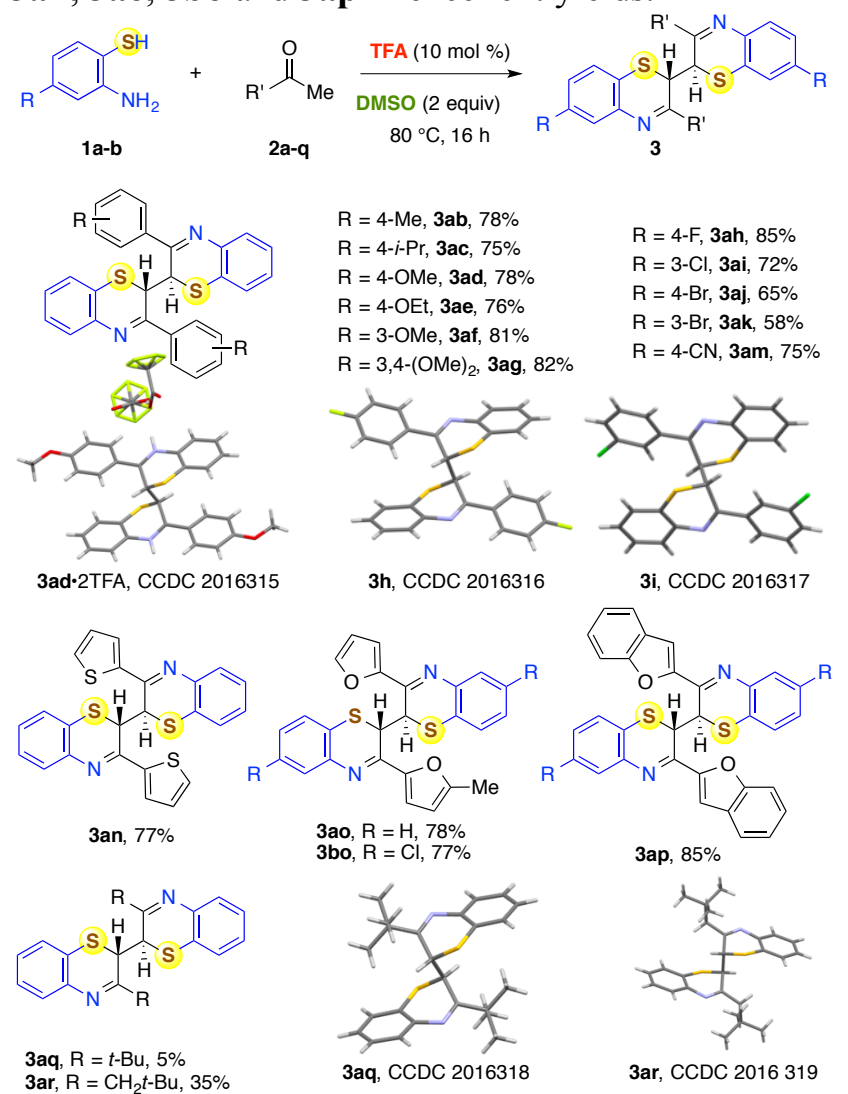

Scheme 3. Reactions of 1a,b with Methyl Ketones 2a-q

As an $\alpha$-enolizable aliphatic methyl ketone, pinacolone $\mathbf{2 q}$ reacted sluggishly, leading to the desired product $\mathbf{3 a q}$ in a low yield, which could be ascribed to the important steric hindrance of the $t$-butyl group. The reactivity is ameliorated with a less sterically demanding ketone such as methyl neopentyl ketone 2r. In this case, although the ketone substrate $2 \mathbf{r}$ is $\alpha, \alpha^{\prime}$-enolizable, the isolated product 3ar was issued from the oxidation that exclusively occurred at the methyl ketone group.

The reaction was next extended to propiophenone 4a (Scheme 4a). To our surprise, while the corresponding bis-1,4-benzothiazine was not formed, we could isolate from the reaction mixture a white solid which was identified as an original heteropropellane 5a (22\%). Based on this observation, the molar ratio 1a:4a was adjusted to 2:1. Gratifyingly, such a simple modification allowed us to increase the yield of $\mathbf{5 a}$ up to $79 \%$. This set of reaction conditions were applied to $p$-substituted propiophenones $4 \mathbf{b}$-d and resulted in the expected heteropropellanes $\mathbf{5 b} \mathbf{b}-\mathbf{5 d}$, which were isolated in high yields by simple filtration in all cases.

With butyrophenone $\mathbf{6 a}$, valerophenone $\mathbf{6 b}$ and hexyl phenyl ketone 6c, neither bis-1,4-benzothiazine nor heteropropellane was formed. the reaction stopped at the formation of the corresponding benzothiazines 7a-c in high yields by ${ }^{1} \mathrm{H}$ NMR of the crude mixtures (Scheme 4b) but their isolation by column chromatography was shown to be problematic due to reactions with oxygen. Indeed, freshly purified samples upon leaving under air turned from bright yellow of benzothiazine 7a-c to dark brown mixtures from which large and single crystals were separated and determined as 2-phenylbenzothiazole $\mathbf{8}$ for all these three cases.

$$
\text { a. Propiophenones: }
$$

Scheme 4. Reactions with Propiophenones and Homologues

On the other hand, $\alpha$-substituted alkyl phenyl ketones such as isobutyrophenone and benzoylcyclohexane were found to yield 3,3-dialkyl1,4-benzothiazines 7d,e, which were bench-stable and could be isolated in high yields (Scheme 5).

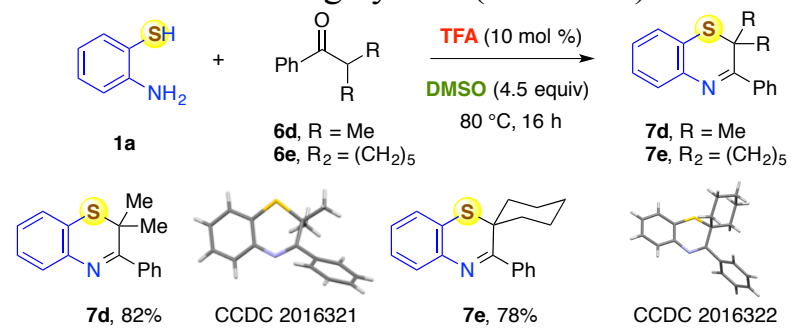

Scheme 5. Reactions with $\alpha$-Substituted Propiophenones

Based on these observations, we tentatively suggest a mechanism (Scheme 6) for the formation of benzothiazines 3, 5a-d and $7 \mathbf{d}-\mathbf{e}$ as well as of benzothiazole $\mathbf{8}$ from autoxidation of 7a-c. The first step was the formation of disulfide $\mathbf{B}$ by oxidation of 1a with DMSO, confirmed by a control experiment. ${ }^{[11]}$ Disulfide $\mathbf{B}$ condensed next with ketone $\mathbf{C}$ to provide imine- enamine D-E. Cyclization of $\mathbf{E}$ led to benzothiazine 7 along with the extrusion of 1a, which was recycled to disulfide B by DMSO (Scheme 6a). Ketones 7 bear a small substituent $(\mathrm{R}=\mathrm{H}$ or $\mathrm{Me}, \mathbf{7} \mathbf{H}$ or $7 \mathrm{Me}$ ) were oxidized easily to sulfoxide by DMSO (Scheme 6b). The rearrangement of sulfoxide $\mathbf{F}$ to sulfonium $\mathbf{J}$ was promoted by acid via intermediates G-I. Dimer 3aa was obtained by the condensation of $\mathbf{J}$ $(\mathrm{R}=\mathrm{H})$ with $\mathbf{7 a}$, which is the enamine form of $7(\mathrm{R}=$ $\mathrm{H})$. 
When $\mathrm{R}=\mathrm{Me}$, the similar condensation is hindered. As a result, a reaction of $\mathbf{J}$ with an additional molecule of $\mathbf{1 a}$ would provide sulfonium $\mathbf{M}$, which underwent a cyclization by the mercapto group from the less hindered face to give $\mathbf{5 a}$ as a single diastereomer.
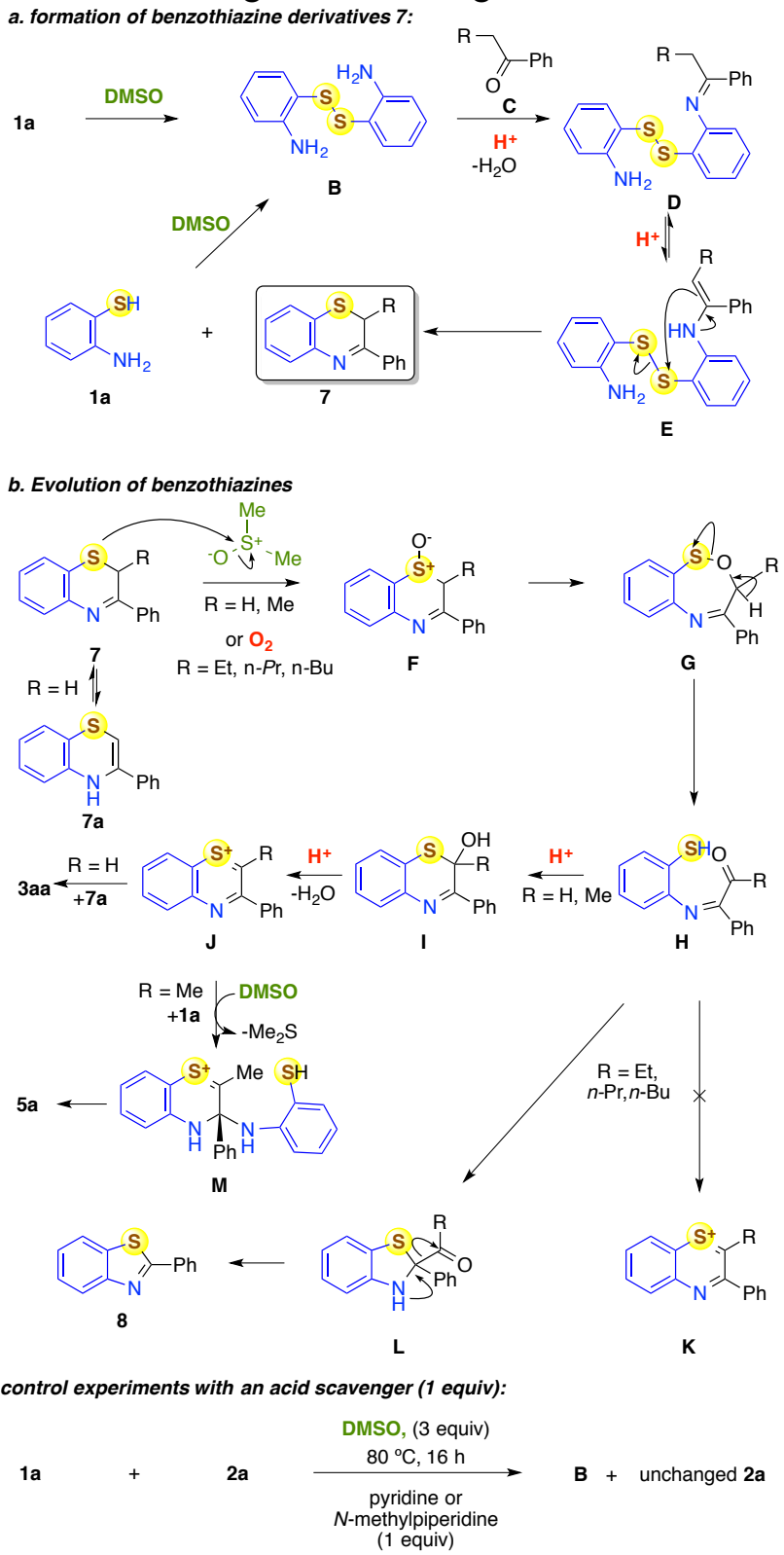

Scheme 6. Proposed reaction pathways

One of the possible reason for the formation of 3aa without any added acid catalyst is the reaction is autocatatalyzed by the acidic thiol function of 2aminothiophenol 1a $\left(\mathrm{p} K_{\mathrm{a}}=6.59\right)^{[12]}$ as well as by other oxygenated acidic species issued from oxidation of the thiol function of 1a by DMSO such as sulfinic and sulfonic acids. To confirm this hypothesis, we performed control experiments in the presence of an organic base (1 equiv) such as pyridine or $N$ methylpiperidine. Under the same conditions of heating (DMSO ( 3 equiv), $80{ }^{\circ} \mathrm{C}, 16 \mathrm{~h}$ ), such base prevented the formation of 3 aa from occurring. While acetophenone remained unchanged, 2aminothiophenol 1a was oxidized mainly into $\mathbf{B}$.

Benzothiazines bearing larger R groups (Et, $n$ - $\mathrm{Pr}, n$ $\mathrm{Bu}$ ) were more stable against oxidation by DMSO but not air-stable, being oxidized by $\mathrm{O}_{2}$ to ketone $\mathbf{H}$. In this case, the transformation of $\mathbf{H}$ to sulfonium $\mathbf{K}$ was hindered by the larger R group. Instead, cyclization of $\mathbf{H}$ to benzothiazoline $\mathbf{L}$ occurred easily. Elimination of RCHO from $\mathbf{L}$ yielded $\mathbf{8}^{\left[{ }^{[9]}\right.}$ The autoxidation of benzothiazines $\mathbf{7 d}, \mathbf{e}$ is totally inhibited by the two $\mathrm{R}$ groups.

The presence of sulfonium $\mathbf{J}(\mathrm{R}=\mathrm{H})$ could be confirmed by trapping experiments with anilines $\mathbf{9 a}, \mathbf{b}$, providing imine 10a,b in moderate yields (Scheme 7). Previously, similar reactions were reported to involve both $\mathrm{O}_{2} / \mathrm{DMSO}$ oxidant and $\mathrm{KI}$ catalyst at $120{ }^{\circ} \mathrm{C}$. ${ }^{[10]}$

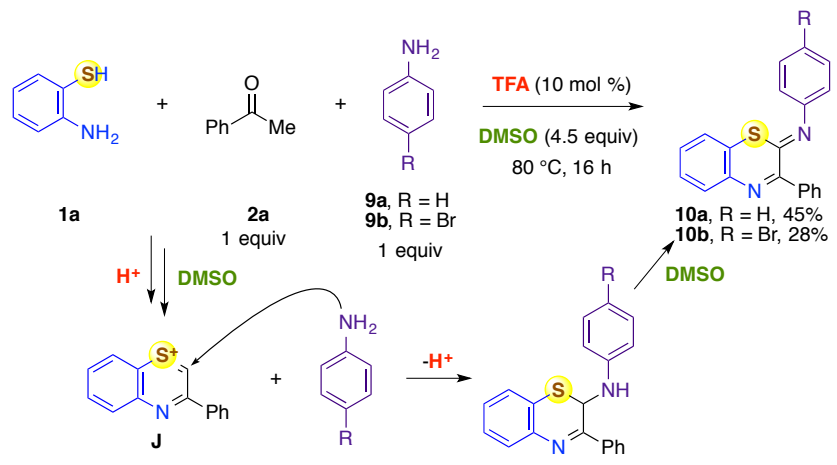

Scheme 7. Three-component Access to $\mathbf{1 0 a}, \mathbf{b}$ via $\mathbf{J}$

Finally, we observed that benzothiazines 7 could be stabilized against oxidation by an electron withdrawing group $\left(\mathrm{R}=\mathrm{CN}\right.$ or $\left.\mathrm{CO}_{2} \mathrm{Et}\right)$ installed next to the sulfur atom (Scheme 8). The reaction of $\mathbf{1 a}$ with ketone $\mathbf{1 1 a}, \mathbf{b}$ resulted in $\mathbf{1 2} \mathbf{a}, \mathbf{b}$ as orange air-stable solids.

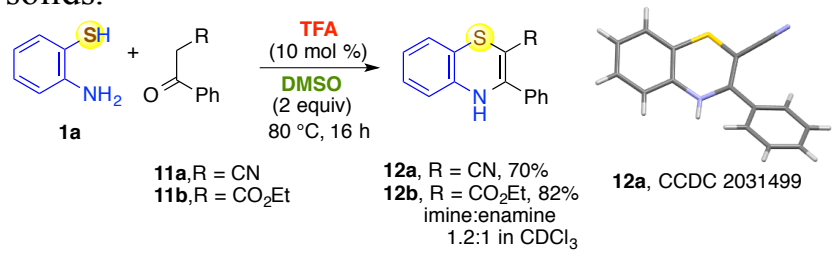

Scheme 8. Reaction with Ketones 11a,b Bearing an EWG

In conclusion, we have developed a simple method for functionalization of aryl alkyl ketones with $o$ aminothiophenols to provide a wide range of 2arylbenzothiazines. The method is highlighted by the use of TFA as an acid catalyst and DMSO in near stoichiometric amount as an oxidant. Although 1,4benzothiazines 7 are common reaction intermediates, the final reaction outcomes were determined by the size and electronic effect of the alkyl group of the ketones. The results presented here confirm that complex structures could be built from simple starting materials under simple conditions. Further study on the mechanism as well as the reaction scopes are ongoing in our laboratory. 


\section{Experimental Section}

General procedure for the synthesis of 3 from 2aminothiophenols 1 and methyl ketone 2 (Table 1 and Scheme 3)

A mixture of 2-aminothiophenol 1 (1 mmol), acetophenone $2(1 \mathrm{mmol})$, TFA $(0.1 \mathrm{mmol}, 11 \mathrm{mg})$ in DMSO $(2 \mathrm{mmol}$, $0.15 \mathrm{~mL}$ ) was stirred in a $7-\mathrm{mL}$ tube closed with a rubber septum at $80{ }^{\circ} \mathrm{C}$ for $16 \mathrm{~h}$. After being cooled to room temperature, the crude reaction mixture was purified as indicated for each compound, by trituration or chromatography on silica gel column.

Products 7d,e and 12a,b were synthesized in the same manner with DMSO $(4.5 \mathrm{mmol}, 0.32 \mathrm{~mL})$. In these cases, the products were purified by chromatography on silica gel column.

Representative procedure for the synthesis of heteropropellanes 5 from 2-aminothiophenol 1 a and propiophenone 4

A mixture of 2-aminothiophenol 1a (2 mmol, $250 \mathrm{mg})$, propiophenone 4a $(1 \mathrm{mmol}, 134 \mathrm{mg})$, TFA $(0.1 \mathrm{mmol}, 11$ $\mathrm{mg})$ in DMSO $(4.5 \mathrm{mmol}, 0.32 \mathrm{~mL})$ was stirred in a $7-\mathrm{mL}$ tube closed with a rubber septum at $80{ }^{\circ} \mathrm{C}$ for $16 \mathrm{~h}$. After being cooled to room temperature, the crude reaction mixture was purified as by trituration and filtration with cold methanol $\left(0-4^{\circ} \mathrm{C}\right)$ to provide heteropropellane 5a as a white solid.

CCDC 2016315-2016319; 2016321-2016322 and 20314982031499 contain the supplementary crystallographic data for 3ad•2TFA, 3ah, 3ai, 3aq, 3ar, 7d, 7e, 5a and 12a respectively in this paper. These data can be obtained free of charge from The Cambridge Crystallographic Data Centre via www.ccdc.cam.ac.uk/data request/cif.

\section{References}

[1] a) R. A. Aitken, K. M. Aitken, In Comprehensive Heterocyclic Chemistry III, Elsevier, 2008, 8, pp 607675; b) Wang, N.; Saidhareddya, P. Jiang, X. Nat. Prod. Rep. 2020, 37, 246; c) M. Feng, B. Tang, S. H. Liang, X. Jiang, Curr. Top. Med. Chem. 2016, 16, 1200; For an example of 1,4-benzothiazines, see: Z. Qiao, H. Liu, X. Xiao, Y. Fu, J. Wei, Y. Li, X. Jiang, Org. Lett. 2013, 15, 2594.

[2] R. Fringuelli, L. Milanese, F. Schiaffella, Mini-Rev. Med. Chem. 2005, 5, 1061.

[3] a) R. H. Thomson, Angew. Chem., Int. Ed. Engl. 1974, 13, 305; b) G. Prota, Melanins and Melanogenesis; Academic Press: San Diego, CA, 1992; c) P. Di Donato, A. Napolitano, Pigm. Cell Res. 2003, 16, 532; d) G. Greco, L. Panzella, L. Verotta, M. d'Ischia, A. Napolitano, J. Nat. Prod. 2011, 74, 675.

[4] J. Habermann, S. V. Ley, J. S. Scott, J. Chem. Soc. Perkin Trans. I 1998, 19, 3127; b) T. V. Beryozkina, N. N. Kolos, V. D. Orlov, R. I. Zubatyuk, O. V. Shishkin, Phosphorus Sulfur Silicon Relat. Elem. 2004, 179, 2153; c) K. C. Nicolaou, P. Baran, Y. Zhong, J. Am. Chem. Soc. 2000, 122, 10246; d) S; Kamila, B. Koh, O. Khan, H. Zhang, E. R. Biehl, J. Heterocycl. Chem. 2006, 43, 1641; e) H. Tawada, Y. Sugiyama, H. Ikeda, Y. Yamamoto, K. Meguro, Chem. Pharm. Bull. 1990, 38, 1238.
[5] For a recent example of oxidative condensation of 2aminothiophenols with enolizable ketones at $110^{\circ} \mathrm{C}$, see: Y. Lin, G. Lu, R. Wang, W. Yi, Org. Lett. 2016, 18, 6424.

[6] T. B. Nguyen, P. Retailleau, Adv. Synth. Catal. 2020, DOI: $10.1002 /$ adsc. 202000535.

[7] For selected examples, see: a) from dibenzoylacetylene: M. I. Ansari, R. Shankar, M. K. Hussain, R. Kant, P. R. Maulik, K. R. Kumar, Hajela, K. J. Heterocyclic Chem., 2011, 48, 1336. from $\alpha, \alpha$-dibromoacetophenones, Prakash, O. Sharma, N. Pannu, K. Synth. Commun. 2007, 37, 1995. From 3-phenyl-5(4H)-isoxazolone: M. H. Rao, A. P. R. Reddy, V. Veeranagaiah, Synth. Commun. 1991, 21,1715 .

[8] X. Huang, N. Rong, P. Li, G. Shen, Q. Li, N. Xin, C. Cui, J. Cui, B. Yang, D. Li, C. Zhao, J. Dou, B. Wang, Org. Lett. 2018, 20, 3332.

[9] J. D. Charrier, C. Landreau, D. Deniaud, F. Reliquet, A. Reliquet, J. C. Meslin, Tetrahedron 2001, 57, 4195.

[10] J. Zhao, Z. Luo, J. Xu, Adv. Synth. Catal. 2020, 362, 1988.

[11] W. E. Fristad, J. R. Peterson, Synth. Commun. 1985, 15, 1 .

[12] R. Fujiki, Y. Kasai, Y. Seno, T. Matsui, T. Shigeta,N. Yoshida, H. Nakano, Phys. Chem. Chem. Phys. 2018, 20, 27272. 


\section{COMMUNICATION}

Umpolung Strategy with 2-Aminothiophenols: Access to 2-Arylbenzothiazine Derivatives from Alkyl Aryl Ketones

Adv. Synth. Catal. Year, Volume, Page - Page
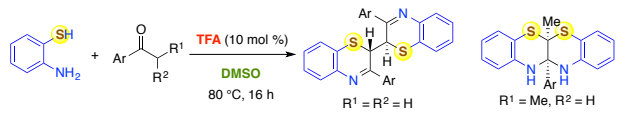

Thanh Binh Nguyen, ${ }^{*, a}$ and Pascal Retailleau ${ }^{\mathrm{a}}$ 